\title{
Evaluation of National Environmental Efficiency Under Uncertainty Using Data Envelopment Analysis
}

\author{
Evangelos Grigoroudis and Konstantinos Petridis
}

\begin{abstract}
The evaluation of environmental practices of each country is a very interesting area which has recently gained significant attention. An analysis, which can provide results for comparisons among countries with different economies, is data envelopment analysis. In this chapter, countries' environmental efficiency is estimated using data envelopment analysis. Applying a slack-based model under the consideration of constant returns to scale and variable returns to scale technologies, a composite index is calculated from the efficiency scores of each model. These models consider both desirable and undesirable outputs. However, especially for undesirable outputs, the data collected are not accurate and could potentially be subject to uncertainty. To handle the uncertainty in the undesirable data, a chanceconstraint DEA model is applied. Results of the deterministic model show that Australia gathers high values of environmental efficiency. However, in the presence of noise in the undesirable data, the rankings of the countries change.
\end{abstract}

Keywords Environmental efficiency $\cdot$ Environmental evaluation · Environmental economics · Data envelopment analysis · Slack-based models · Composite index

\section{Introduction}

The term environment refers to anything that surrounds an object. In natural sciences, as well as in engineering, a system is the part of the world being studied, and the environment is anything outside its boundaries. There can be interactions and exchanges of matter, energy, or information between the system and the environment.

\footnotetext{
E. Grigoroudis $(\bowtie) \cdot K$. Petridis

School of Production Engineering and Management, Technical University of Crete, Chania, Greece

e-mail: vangelis@ergasya.tuc.gr
} 
Human interventions have affected the environment, disturbing the environmental balance, altering its natural processes, and degrading the quality of human life. One of the most dangerous human interventions' side effects is that they jeopardize the sustainability of the planet while creating many problems and serious environmental accidents. The major modern environmental problems known as "global environmental problems" mainly consist of ozone depletion, greenhouse effect, pollution of the environment in general, degradation, and pollution of key environmental resources such as air, water (lakes, seas, and oceans), soil, desertification, and biodiversity loss.

A great time period has passed for the aforementioned risks to be fully understood, and this is evidenced by recent facts of degradation and destruction of the environment. Unreasonable human intervention in the environment and abusive use and exploitation of natural wealth lead to disastrous consequences. Primary goods, which were considered inexhaustible or unaltered, are slowly degraded.

As noted by Grigoroudis et al. (2012), the environment provides the economy with resources (e.g., water, air, fuels, food, metals, minerals, and drugs), services (e.g., the cycles of $\mathrm{H}_{2} \mathrm{O}, \mathrm{C}, \mathrm{CO}_{2}, \mathrm{~N}, \mathrm{O}_{2}$; photosynthesis; and soil formation), and mechanisms to absorb waste. Economic growth is based on these three services, and since the global ecosystem does not grow, economic growth cannot continue indefinitely. The concepts of sustainability and sustainable development have received much attention among policy-makers and scientists as a result of the existence of limits to growth and the dramatic environmental changes of the last decades.

The term of environmental efficiency was devised by the World Business Council for Sustainable Development (WBCSD) in 1992 in its "Changing Course" publication. It is based on the idea of creating more goods and services using less resources and creating less waste and pollution. It is a philosophy that aims to minimize ecological impacts while maximizing the efficiency of the processes of a production unit. The term has become synonymous with a concept oriented toward sustainable development.

Uncertainty, as a term, is inherited in data measurement in the presence of noise, while it is also present when dealing with the environment. The difficulty of uncertainty is its stochastic nature which is approximated with stochastic procedures and models. Nevertheless, the measurement of stochasticity or uncertainty is never accurate. It can, however, be estimated under various assumptions.

The economic activities that are conducted around the world have a direct effect on the environment, which is affected irrespective of the geographical location. A source of pollution, due to excess of emissions from industry or any related production process, affects the total environment. Nevertheless, modern way of living and globalization have led to form the economies without considering the environment, since environmental protection does not add value to economic activities. To reduce this phenomenon, several environmental protocols and directives have been agreed in an effort to regulate terms and undesirable outputs from the production process of national economies. Therefore, a methodological framework is needed to measure the effect at which the environment is affected from the economic activity of each country and try to find an "equilibrium" point at which each country can increase its productivity without putting an extra burden on the environment. 
Estimating environmental efficiency gives emphasis on producing the maximum possible economic output, using minimum resources, and at the same time minimizing environmental impacts. Therefore, it is a process different from environmental performance estimation. The estimation of environmental efficiency is a rather difficult problem mainly because the concept does not have a universal definition and usually the applied measurement framework serves also as a definition context. In practice, this makes more difficult the selection of appropriate indicators, while data availability is always a significant shortcoming when estimating environmental efficiency in a national level.

The aim of this chapter is to present a methodological framework for the measurement of environmental efficiency and to highlight the indicators of evaluation of the studied units. The data used in this study refer to a 12-year period (1992-2003) and concern 108 countries from all over the world, belonging to various social, political, and economic categories. A nonparametric method, data envelopment analysis (DEA), is used to estimate national environmental efficiencies. Moreover, a chance-constraint DEA model with desirable and undesirable outputs is applied in the proposed approach, assuming that the undesirable outputs (harmful gas emissions) are subject to noise. This incorporation of uncertainty in the applied DEA models may be considered as the main contribution of this research, while the examination of alternative measurement variables gives the ability to compare how different indicators may affect the environmental efficiency scores.

The chapter is organized in four more sections. Section 2 presents briefly a literature review of environmental efficiency evaluation focusing mainly on DEA models. The methodological background of the proposed approach is given in Sect. 3 , where, in addition to the main principles of DEA models, the proposed slackbased model is presented. Moreover, Sect. 3 presents a chance-constraint DEA model in order to handle the uncertainty of environmental data. The results of the proposed approach in a set of 108 countries covering a period from 1992 to 2003 are given in Sect. 4. Section 5, finally, summarizes some concluding remarks and discusses potential extensions of the research.

\section{Literature Review}

Based on Farrell's original ideas (Farrell 1957), DEA was firstly used in Germany by Brockhoff in 1970 to measure R\&D and production efficiency (Brockhoff 1970). Within an environmental context, DEA was first used in 1986 by Färe, in a sample of steam power stations in the United States, to measure the impact of environmental constraints and measures (Färe et al. 1986).

A mathematical programming approach to environmental management and industrial efficiency is outlined in 1994 by Haynes as an alternative to decision support processes related to the monitoring of pollutant reductions. Färe et al. (1996) applied DEA using US data on fossil fuels that are burning power companies, resulting in pollution and efficiency indicators. DEA models have been also used to compare the efficiency of several units of a company or various production units 
in a sector with specific characteristics and environmental constraints (Tyteca 1996). As a comparison technique, DEA has been used for OECD countries to assess environmental performance based on $\mathrm{CO}_{2}$ emissions (Zofío and Prieto 2001). Assessment of business participation in sustainable development has been also examined with the use of DEA (Callens and Tyteca 1999). The study of performance indicators with ecological and environmental extensions has been proposed by Dyckhoff and Allen (2001).

The estimations of environmental efficiency measures have also been examined in several studies. For example, Reinhard et al. (2000) compare different efficiency estimation approaches (DEA and stochastic frontier analysis) for the case of Dutch dairy farms. They define environmental efficiency as the ratio of minimum feasible to observed use of multiple environmentally detrimental inputs, conditional on observed levels of output and conventional inputs.

Environmental efficiency through energy consumption and carbon dioxide emissions has been measured using DEA with data from 17 Middle East and North African countries (Ramanathan 2005). The environmental performance of the states of America has been also evaluated under the assumption that air pollution is mainly a by-product of the production process for the years 1972-1983 and 1985-1986 (Zaim 2004). Korhonen and Luptacik (2004) applied a two-stage DEA approach to 24 European power plants. In the first stage, the problem is decomposed in two parts:

(a) The problem of measuring the technical efficiency (such as the ratio of the desired costs to the entrances)

(b) The problem of measuring the so-called ecological efficiency (such as the ratio of the desired costs to the unwanted ones)

The performance indicators of each stage are then combined into one. In the second stage, pollutants and system inputs are treated the same as the aim is to increase the desired costs and reduce pollutants and inputs.

Triantis and Otis (2004) developed a performance measurement model, which examines environmental measures and the harmful ecological consequences of the production process over time. More specifically, they present a pair-based approach that examines production and environmental efficiency and evaluate desirable environmental interactions of the production system through various combinations of inputs and outputs. Zhou et al. $(2006,2008)$ proposed a non-radial DEA approach for assessing environmental performance. The time period of this analysis spans from 1995 to 1997 , while the 26 countries of the OECD are treated as decisionmaking units.

Prieto and Zofío (2007) presented a network efficiency analysis model that allows possible increases in technical efficiency by comparing technologies that correspond to different economies. Input-output tables represent a network where various nodal factors use primary inputs to produce intermediate inputs and outflows to meet the final demand. The proposed model optimizes the underlying multistage technologies, defining the best financial practice. The model is applied to a total of five OECD countries in the period from 1970 to 1990. Zhou et al. (2007) in the context of environmental efficiency show an extension of the DEA and more specifically the nonincreasing returns to scale (NIRS) model and the variable returns to scale (VRS). 
A comprehensive literature review of DEA models applied to energy and environment may be found in Sueyoshi et al. (2017). Their review covers almost 700 articles from the 1980 s to 2010 s. The authors report an increased number of DEA articles, particularly after the 2000s, and discuss three major future research directions:

(a) Technology heterogeneities and time lag: The authors note that different organizations and different regions may have different engineering capabilities, so that they have many different types of technology heterogeneities among them. This, as well as the time lag that is always associated with technology development, should be considered in DEA modeling.

(b) Statistical inference: The authors argue that one of the major shortcomings of DEA environmental assessment is that it does not have a statistical inference at the level of statistics and econometrics; therefore, the exploration on the statistical inference on DEA may provide an important future research direction.

(c) Applications to China: The authors emphasize that China is the world's largest energy consumer and carbon emission contributor. Thus, it is important, through the application of DEA models, to identify better ways to reduce Chinese energy uses and carbon emissions.

In the same context, Mardani et al. (2017) provide a review, focusing however in energy efficiency. Their review covers 144 published scholarly papers appearing in 45 high-ranking journals between 2006 and 2015 and shows that DEA may be a good evaluation tool on energy efficiency issues, when the production function between the inputs and outputs is virtually absent or extremely difficult to acquire.

Stochasticity is part of the everyday operations; therefore, efficiency measurement calls for probability calculations. In the context of DEA, several stochastic models have been proposed in the literature over the years. The first DEA stochastic model was applied by Charnes and Cooper (1963). Following their paper, the stochastic DEA modeled with chance constraints has grown significantly.

Stochasticity has been incorporated in DEA for measuring technical efficiency and inefficiency indices (Cooper et al. 2002). In the majority of the relevant papers, modeling involved the stochastic nature of $\mathrm{CO}_{2}$ emissions and the impact on efficiency or energy production. Gutiérrez et al. (2008) presented a methodology to analyze the gradual secular trends present in the time evolution of certain endogenous variables, which are of particular interest in environmental research. Also, several stochastic environmental performance indices have been constructed (Baležentis et al. 2016; Zha et al. 2016).

DEA's applications in environmental efficiency and the assessment of ecological constraints are significantly increasing. DEA gains ground in the preferences of researchers who have been using it extensively especially in recent years. 


\section{Methodology}

\subsection{General}

In recent years, great emphasis has been placed on efficiency measurement methods. Efficiency is defined as the ability of a unit to efficiently transform, with a generally unknown production mechanism, inputs into outputs. Traditional econometric methods have been used to evaluate efficiency. These techniques were designed to calculate theoretically analytical production functions. One of the shortcomings of these methods is that they cannot handle multiple inputs but only a single output. Data envelopment analysis (DEA) has been introduced to handle multiple inputs and multiple outputs in order to evaluate homogenous units, the decision-making units (DMUs).

DEA technique is widely applied in a series of studies to estimate relative unit efficiency, with respect to a set of similar units that have multiple inputs and outputs. In DEA, DMUs consume inputs to transform them into outputs. Therefore, a DMU includes the activities of many different organizations as mentioned above. Outputs are defined as products or services produced by each unit, while inputs are generally defined as resources used to produce outputs (land, labor, fuel, etc.).

Figure 1 shows a graphical representation of a DEA model in the context of this study, where a DMU corresponds to the production process of a national economy, while the inputs refer to the main resources used in this production process and may include national labor force, available capital, or energy produced. On the other hand, the outputs of the production process include both desirable (e.g., national income) and undesirable results (e.g., emissions, waste).

\subsection{Envelopment Models}

The envelopment models considered in this study include both input- and outputoriented models. In particular, the input-oriented DEA model has the following form:

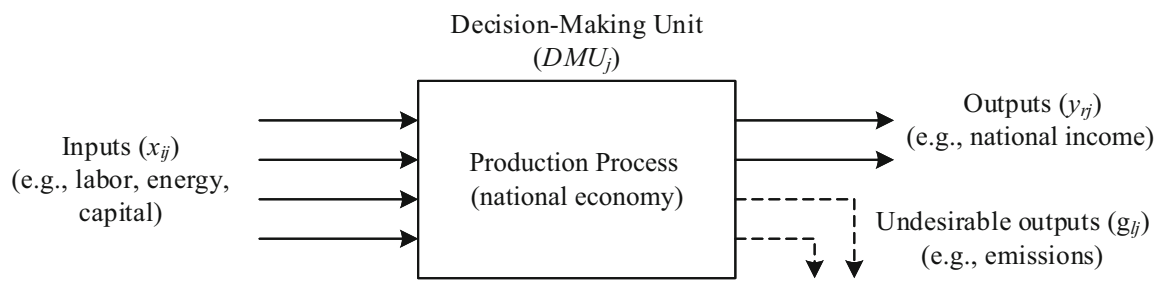

Fig. 1 Graphical illustration of a production process in a national economy 


$$
\begin{aligned}
& \min \theta-\varepsilon\left(\sum_{i=1}^{m} s_{i}^{-}+\sum_{r=1}^{s} s_{r}^{+}\right) \\
& \text {s.t. } \\
& \sum_{j=1}^{n} x_{i j} \cdot \lambda_{j}+s_{i}^{-}=x_{i o} \cdot \theta, i=1, \ldots, m \\
& \sum_{j=1}^{n} y_{r j} \cdot \lambda_{j}-s_{r}^{+}=y_{r o}, r=1, \ldots, s \\
& \lambda_{j}, s_{i}^{-}, s_{r}^{+} \geq 0, \forall j, i, r \\
& \theta \text { free }
\end{aligned}
$$

The objective function in this model is to minimize free variable $\theta$, which measures the efficiency of each DMU. The evaluation of each DMU's efficiency is conducted upon a predetermined set of $i$ inputs $\left(x_{i j}\right)$ and $r$ inputs $\left(y_{r j}\right)$ for each $\mathrm{DMU}_{j}$. As a consequence, the aim of the previous model is to determine the least possible level of available inputs $\left(x_{i o}\right)$, for a DMU under examination $\left(\mathrm{DMU}_{o}\right)$, which are capable to produce the desired level of outputs $\left(y_{i o}\right)$. Variables $\lambda_{j}$ are the peers of each $\mathrm{DMU}_{j}$; peers are used in order to provide information regarding the proximity of the DMU under investigation with other DMUs. The mathematical formulation (1) represents a linear programming (LP) model which is solved for each DMU under examination (i.e., $\mathrm{DMU}_{o}$ ). If, for example, $\mathrm{DMU}_{5}$ has in its reference set $\mathrm{DMU}_{2}$ and $\mathrm{DMU}_{6}$, then $\lambda_{2}, \lambda_{6} \neq 0$. Nonnegative variables $s_{i}^{-}$and $s_{r}^{+}$ are slack variables corresponding to the inputs and outputs, respectively, while $\varepsilon$ is a small number. A fully efficient DMU is the one with $\theta^{*}=1$ and $s_{i}^{-}=s_{i}^{+}=0$, whereas $\theta^{*}$ is the optimal value of LP model (1) for each DMU under examination. The range of values for input efficiency is $0 \leq \theta \leq 1$.

Similarly, the output-oriented DEA model is defined as follows:

$$
\begin{aligned}
& \max \varphi+\varepsilon\left(\sum_{i=1}^{m} s_{i}^{-}+\sum_{r=1}^{s} s_{r}^{+}\right) \\
& \text {s.t. } \\
& \sum_{j=1}^{n} x_{i j} \cdot \lambda_{j}+s_{i}^{-}=x_{i o}, i=1, \ldots, m \\
& \sum_{j=1}^{n} y_{r j} \cdot \lambda_{j}-s_{r}^{+}=y_{r o} \cdot \varphi, r=1, \ldots, s \\
& \lambda_{j}, s_{i}^{-}, s_{r}^{+} \geq 0, \forall j, i, r \\
& \varphi \text { free }
\end{aligned}
$$

The objective function in this case is to minimize free variable $\varphi$ which measures the efficiency of each DMU, where the variables $x_{i j}, y_{r j}, s_{i}^{-}, s_{i}^{+}$, and $\lambda_{j}$ are defined similar to LP (1). Model (2) represents also a LP model which is solved for each DMU under examination (i.e., $\mathrm{DMU}_{o}$ ). A fully efficient DMU in this case is the one with $\varphi^{*}=1$ and $s_{i}^{-}=s_{i}^{+}=0$, whereas $\varphi^{*}$ is the optimal values of LP model (2) for 
each DMU under examination. For output-oriented efficiency, we have $\varphi \geq 1$, and in order to capture the degree of inefficiency of a DMU, the reciprocal is calculated, such that $0 \leq 1 / \varphi^{*} \leq 1$.

Following the discussion about the orientation of input and output DEA models, the optimal values of efficiency variables are of great interest as the projections of inputs and outputs to the efficient frontier are calculated. To do that, the following equations are considered:

$$
\begin{gathered}
\left\{\begin{array}{l}
\widehat{x}_{i j}=x_{i j} \cdot \theta^{*}-s_{i}^{-*} \\
\hat{y}_{r j}=y_{r j}-s_{r}^{+*}
\end{array}\right. \text { (input orientation) } \\
\left\{\begin{array}{l}
\hat{x}_{i j}=x_{i j}-s_{i}^{-*} \\
\hat{y}_{r j}=y_{r j} \cdot \varphi^{*}-s_{r}^{+*}
\end{array}\right.
\end{gathered}
$$

\subsection{Slack-Based Models}

Several environmental performance indicators have been constructed, combining DEA with various types of performance measurement. As mentioned above, in order for a DMU to be fully efficient, $\theta^{*}=1$ and $s_{i}^{-}=s_{i}^{+}=0$. However, two DMUs may have the same efficiency (maximum efficiency), despite the fact that their input and output data may indicate a difference in this measure. In terms of DEA, only one of these DMUs is fully efficient. This is an inherent inefficiency of the indicator which is fixed by considering slack-based measure (SBM) models.

The SBM model considering desirable outputs has the following form:

$$
\begin{aligned}
& \theta_{1}=\min \frac{1-\frac{1}{m} \sum_{i=1}^{m} \frac{s_{i}^{-}}{x_{i o}}}{1-\frac{1}{s} \sum_{r=1}^{s} \frac{s_{r}^{+}}{y_{r o}}} \\
& \text { s.t. } \\
& \sum_{j=1}^{n} x_{i j} \cdot \lambda_{j}+s_{i}^{-}=x_{i o}, i=1, \ldots, m \\
& \sum_{j=1}^{n} y_{r j} \cdot \lambda_{j}-s_{r}^{+}=y_{r o}, r=1, \ldots, s \\
& \lambda_{j}, s_{i}^{-}, s_{r}^{+} \geq 0, \forall j, i, r
\end{aligned}
$$


Similarly, the SBM model with undesirable outputs can be defined as follows:

$$
\begin{aligned}
& \theta_{2}=\min \frac{1-\frac{1}{m} \sum_{i=1}^{m} \frac{s_{i}^{-}}{x_{i o}}}{1-\frac{1}{s} \sum_{r=1}^{s} \frac{s_{r}^{+}}{y_{r o}}} \\
& \sum_{j=1}^{\text {s.t. }} x_{i j} \cdot \lambda_{j}+s_{i}^{-}=x_{i o}, i=1, \ldots, m \\
& \sum_{j=1}^{n} y_{r j} \cdot \lambda_{j}-s_{r}^{+}=y_{r o}, r=1, \ldots, s \\
& \sum_{j=1}^{n} g_{l j} \cdot \lambda_{j}=g_{l o}, l=1, \ldots, d \\
& \lambda_{j}, s_{i}^{-}, s_{r}^{+} \geq 0, \forall j, i, r
\end{aligned}
$$

The previous model examines both desirable $\left(y_{r j}\right)$ and undesirable $\left(g_{l j}\right)$ outputs.

Models (5) and (6) are SBM models under constant returns to scale (CRS) technology. The environmental indicator is based on the efficiency scores derived from these models. With the addition of the constraint $\sum_{j} \lambda_{j}=1$, the aforementioned models are solved under the assumption of variable returns to scale (VRS).

Having obtained $\theta_{1}^{*}$ and $\theta_{2}^{*}$, the following slack-based efficiency measure for modeling environmental performance may be defined (Zhou et al. 2006):

$$
\mathrm{SBEI}=\frac{\theta_{1}^{*}}{\theta_{2}^{*}}
$$

This index is able to measure the impact of environmental constraints and standards on efficiency. If the index value is equal to the unit, then the two partial indices $\theta_{1}^{*}$ and $\theta_{2}^{*}$ are equal. This means that there are no undesirable exits or that the environmental constraints do not affect the entire production process at all. Finally, the degree of impact of these undesirable costs can be estimated by type 1 - SBEI.

One of the advantages of the proposed approach is that with the use of DEA, efficiency is calculated based on composite environmental indices (slack-based environmental index, SBEI) which integrate both desirable and undesirable outputs. In addition to SBEI, the opportunity cost can be calculated due to environmental regulations and constraints. On the other hand, the main weaknesses of the proposed approach are based on the limitations of all DEA models. More specifically, DEA models are able to provide relative efficiency scores for the examined DMUs, but they cannot estimate absolute efficiency results. In addition, measurement errors in the assumed inputs/outputs may affect the stability of the provided results, given that DEA is an extreme point method. 


\subsection{Incorporating Uncertainty}

One of the major problems in real-life applications is the uncertainty that lies in the collected data and the examined operations. Since the values that are provided do not represent the "real" image of the data, due to the presence of noise, the data are by nature stochastic. In this study, it is assumed that the undesirable outputs $\left(\mathrm{CO}_{2}, \mathrm{NOx}\right.$, and SOx emissions) are stochastic. The stochastic variable that models the undesirable emissions is denoted with $\widehat{g}_{l j}$, while $\bar{g}_{l j}$ is the corresponding expected value. In order to measure the stochastic efficiency, the following model is applied (Zha et al. 2016):

$$
\begin{aligned}
& \min \theta \\
& \sum_{j=1}^{\text {s.t. }} x_{i j} \cdot \lambda_{j}+s_{i}^{-}=\theta \cdot x_{i o}, i=1, \ldots, m \\
& \sum_{j=1}^{n} y_{r j} \cdot \lambda_{j}-s_{r}^{+}=y_{r o}, r=1, \ldots, s \\
& \sum_{j=1}^{n} g_{l j} \cdot \lambda_{j}+s_{l}^{+}=\theta \cdot g_{l o}, l=1, \ldots, d \\
& \sum_{j=1}^{n} \lambda_{j}\left[\bar{g}_{l j}+b_{l j} \cdot \Phi^{-1}\left(\beta_{l j}\right)\right]=\theta \cdot \bar{g}_{l o}, l=1, \ldots, d \\
& \lambda_{j}, s_{i}^{-}, s_{r}^{+}, s_{l}^{+} \geq 0, \forall j, i, r, l
\end{aligned}
$$

The aim of the previous model is to minimize the efficiency taking into account both desirable and undesirable outputs. An additional constraint is integrated in the DEA model to capture the stochasticity of the data. More specifically, $b_{l j}$ denotes the standard deviation of the undesirable output $l$ for each $\mathrm{DMU}_{j}$, whereas $\Phi^{-1}\left(\beta_{l j}\right)$ is the inverse cumulative distribution of level $\beta_{l j}$. The results of the efficiency $\theta$ can potentially receive values larger than 1 . If $\theta>1$, then the corresponding DMU is stochastic super-efficient; if $\theta=1$ and all the slacks equal to 0 , then the corresponding DMU is stochastic efficient, while if $\theta<1$, the corresponding DMU is stochastic inefficient.

\subsection{Data and Modeling}

In this section, the selected data and the alternative modeling formulations in the examined problem are presented. The selection of appropriate data is based on previous studies, as well as on the rationale of environmental efficiency. Also, the set of countries (DMUs) examined in this study is quite large in order to capture different social, political, and economic conditions. 
As already mentioned, the examined DMUs in the presented DEA models correspond to countries, in order to study their national production process in terms of environmental efficiency. The analysis considers a total of 108 countries covering different geographic areas and economies. However, the number of examined countries may differ in the alternative DEA models, due to data availability.

Regarding the inputs, four types of data were used, including the following indicators:

1. Labor force $\left(10^{6}\right.$ people): It comprises people ages 15 and older who supply labor for the production of goods and services during a specified period. It includes people who are currently employed and people who are unemployed but seeking work as well as first-time job-seekers ${ }^{1}$.

2. Population $\left(10^{6}\right.$ people): It is based on the de facto definition of population (midyear estimates), which counts all residents regardless of legal status or citizenship $^{2}$. It may be used as a proxy of labor force, since the previous indicator does not include everyone working in a national economy.

3. Gross capital formation (current US dollars): It consists of outlays on additions to the fixed assets of the economy plus net changes in the level of inventories ${ }^{3}$. It is considered as a major resource of a national economy in the context of DEA modeling.

4. Primary energy supply production $\left(10^{6}\right.$ toe): It is defined as energy production plus energy imports, minus energy exports, minus international bunkers, and then plus or minus stock changes ${ }^{4}$. It is also considered as a major resource of any national economy's production process.

All of these resources are used in a general production process by countries and produce desirable and undesirable results.

The outputs of the study are divided into desirable and undesirable outputs. More specifically, the desirable output is the gross domestic product (GDP), while the undesirable outputs are carbon dioxide $\left(\mathrm{CO}_{2}\right)$ emissions, sulfur dioxide $\left(\mathrm{SO}_{2}\right)$ emissions, and nitrogen dioxide $\left(\mathrm{NO}_{2}\right)$ emissions. The definition of outputs is as follows:

1. Gross domestic product (current US dollars): GDP at purchaser's prices is the sum of gross value added by all resident producers in the economy plus any product taxes and minus any subsidies not included in the value of the products ${ }^{5}$.

2. $\mathrm{CO}_{2}$ emissions $(\mathrm{kt})$ : Carbon dioxide emissions are those stemming from the burning of fossil fuels and the manufacture of cement. They include carbon

\footnotetext{
${ }^{1}$ World Bank Indicators (https://data.worldbank.org/indicator/SL.TLF.TOTL.IN?view=chart)

${ }^{2}$ World Bank Indicators (https://data.worldbank.org/indicator/SP.POP.TOTL?view=chart)

${ }^{3}$ World Bank Indicators (https://data.worldbank.org/indicator/NE.GDI.TOTL.CD?view=chart)

${ }^{4}$ OECD Data (https://data.oecd.org/energy/primary-energy-supply.htm)

${ }^{5}$ World Bank Indicators (https://data.worldbank.org/indicator/NY.GDP.MKTP.CD?view=chart)
} 
dioxide produced during consumption of solid, liquid, and gas fuels and gas flaring ${ }^{6}$.

3. $\mathrm{SO}_{2}$ emissions (kt): It arises from the oxidation, during combustion, of the sulfur contained within fossil fuels. Fossil fuels, including coal, oil, and to a lesser extent gas, contain sulfur in both organic and inorganic forms ${ }^{7}$.

4. $\mathrm{NO}_{2}$ emissions (kt): It primarily gets in the air from the burning of fuel, and it forms from emissions from cars, trucks, and buses, power plants, and off-road equipment ${ }^{8}$.

The examined alternative models include both slack-based and stochastic DEA approaches, which consider different inputs that are consumed to produce different outputs (desirable and undesirable).

Specifically, the first slack-based model (model A) includes inputs that relate to population of the country and energy supply. These inputs are consumed to produce a desirable output (GDP) and three undesirable outputs $\left(\mathrm{CO}_{2}, \mathrm{SO}_{2}, \mathrm{NO}_{2}\right)$. The number of the countries used in this model is 108 from all over the world based on an amalgamation of different socioeconomic factors. The time period of the data spans from 1992 to 2003.

The second slack-based model (model B) is based on the underlying assumptions of the previous model. Three inputs and four outputs are considered here as well. The total number of DMUs (countries) is 104 and consists of countries of the world from various socioeconomic stratifications. In this model, a desirable output (GDP) and three undesirable outputs $\left(\mathrm{CO}_{2}, \mathrm{SO}_{2}, \mathrm{NO}_{2}\right)$ are considered which are produced from the consumption of three inputs, namely, labor force, gross capital formation, and primary energy supply. The data for the considered countries cover the period from 1992 to 2003.

Finally, the stochastic DEA model examined in this study is similar to model A, where the inputs include population and energy supply, while the outputs refer to GDP (desirable output) and $\mathrm{CO}_{2}, \mathrm{SO}_{2}$, and $\mathrm{NO}_{2}$ emissions (undesirable outputs). A total of 101 countries examined in this model and the time period of the data spans from 1992 to 2003.

\section{Results}

The results of the three alternative DEA models are presented in this section. Each model is applied separately with the data from time period 1992 to 2003. Since the analysis considers spatiotemporal data regarding inputs and outputs, a geometrical average is presented for each model.

\footnotetext{
${ }^{6}$ World Bank Indicators (https://data.worldbank.org/indicator/EN.ATM.CO2E.KT?view=chart)

${ }^{7}$ European Environmental Agency (https://www.eea.europa.eu/data-and-maps/indicators/eea-32sulphur-dioxide-so2-emissions-1/assessment-3)

${ }^{8}$ US Environmental Protection Agency (https://www.epa.gov/no2-pollution)
} 


\subsection{SBEI Results for Model A}

The geometric mean of SBEI for model A is presented in Fig. 2, where the different shades of color represent different values of SBEI (darker shades represent higher SBEI values than lighter shades). The countries that were not considered in the analysis are painted with gray. Based on these results, we may observe that there is a wide selection of countries with average SBEI values in the range $[0,0.2]$. Some of these countries are developed with strong economies and big influence (Canada, Germany, France, or Italy), and some are developing countries (Ethiopia, Pakistan, or Tanzania).

The most and the least environmental efficient countries are shown in Table 1. The countries that are fully efficient, in terms of SBEI (i.e., SBEI = 1), are Australia, Cyprus, Hong Kong, and Luxembourg. Especially for Luxembourg, it should be noted that it is a model country for environmental and economic measurements, which is partly ought to its legislation framework. The very small annual energy output (which is an input to our DEA model), coupled with its relatively large GDP (desirable output) and low emissions allow it to dominate the top efficiency. It should be also emphasized that the country's economy is based on the provision of services and not on industry or on the production of products. This is decisive for the country's environmental efficiency. The most important feature of Hong Kong's case is the annual energy supply.

On the contrary, countries such as China, India, or even Russia are in the last places, mainly because of their large population, their annual energy supply (input data), and their pollutants (output). More specifically, China, which is a country with a large population, would be expected to have the room for more emissions. But its

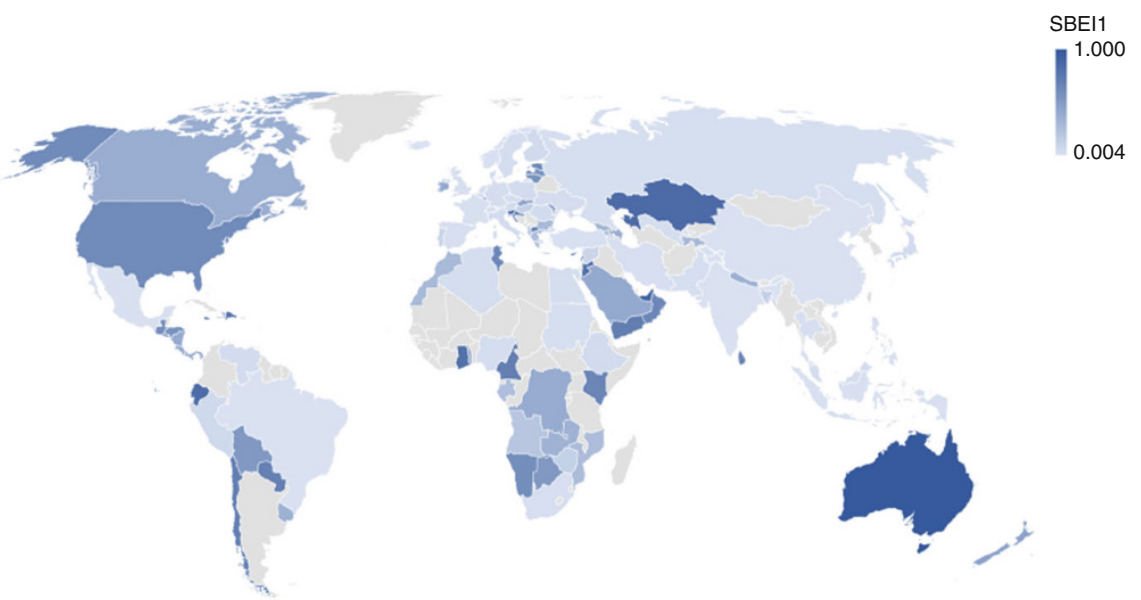

Fig. 2 SBEI results for model A 
Table 1 Most and least environmental efficient countries (model A)

\begin{tabular}{l|l|l}
\hline Efficiency & Countries & SBEI \\
\hline Most efficient countries & Australia & 1.000 \\
\cline { 2 - 3 } & Cyprus & 1.000 \\
\cline { 2 - 3 } & Hong Kong & 1.000 \\
\cline { 2 - 3 } & Luxembourg & 1.000 \\
\cline { 2 - 3 } & United Arab Emirates & 0.915 \\
\hline Least efficient countries & Indonesia & 0.012 \\
\cline { 2 - 3 } & Brazil & 0.007 \\
\cline { 2 - 3 } & Iceland & 0.005 \\
\cline { 2 - 3 } & China & 0.004 \\
\cline { 2 - 3 } & India & 0.004 \\
\hline
\end{tabular}

annual energy supply does not follow the same figures. In addition, countries such as Russia or the United States show higher amounts of energy supply. Also, as mentioned before, pollutant emission values in these countries are among the highest, which is justified by a large percentage of the large population and energy supply. Nevertheless, a driving factor for this increase in the pollutant emissions is associated with high GDP values (which is considered as a desirable output).

\subsection{SBEI Results for Model B}

The results of model $\mathrm{B}$ are significantly different from those of the model A presented in the previous section. This is attributed to the fact that different inputs are considered in this model. Since the consideration of the examined models was based on the minimization of inputs, the additional input effectively enabled the comparisons of the DMUs to be made easier to achieve. Excluding the population, which is a non-variable entry (except in extremely rare cases such as China where there is a legal limitation on birth rates), DMUs can now change their workforce or gross capital formation to improve the efficiency. By introducing additional variables, the degrees of freedom are increased, and the environmental efficiency of a country increases.

Figure 3 presents the results for the geometric mean of SBEI. The different shades of color represent different values of SBEI (darker shades represent higher SBEI values than lighter shades). The countries that were not considered in the analysis are painted with gray.

The most and the least efficient countries based on model B are presented in Table 2, where we may observe that Australia, Hong Kong, and Luxembourg remain as fully efficient countries, with the addition of smaller or less developed economies (e.g., Estonia, Israel, Jordan, Kazakhstan, Moldova). On the other hand, the least efficient countries include Gabon, Japan, Congo, while Indonesia and China remain as low efficient counties compared to model A.

However, it can be noted that this model has less discrimination power since the majority of the countries have higher SBEI values than model A. 


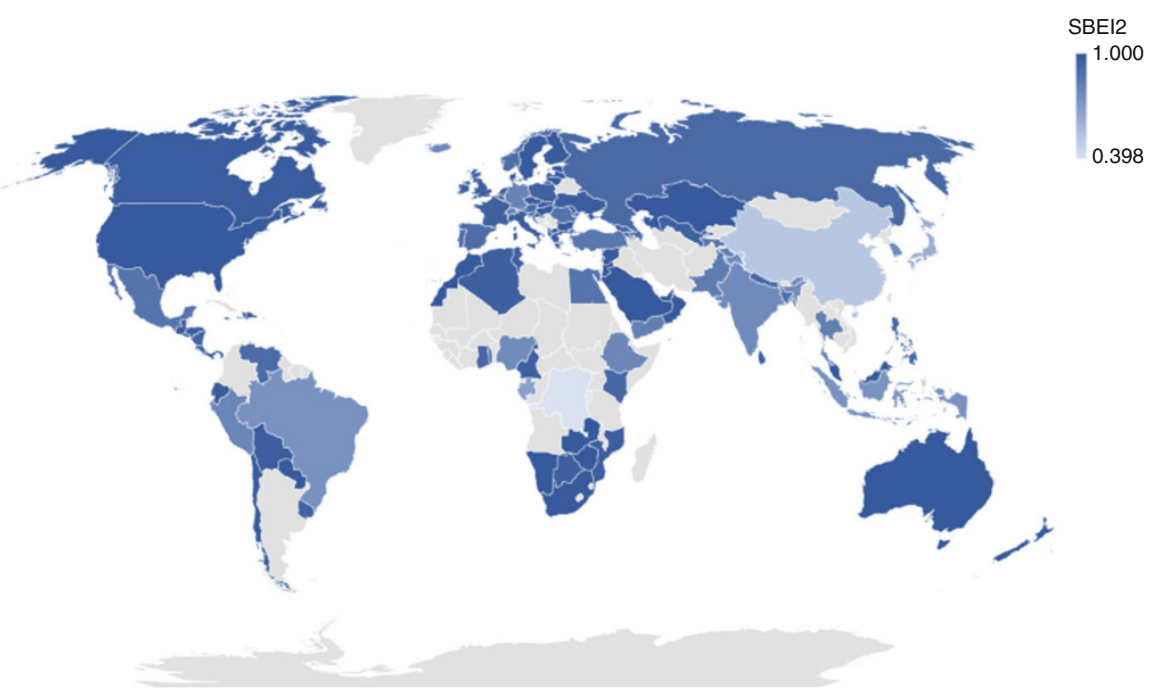

Fig. 3 SBEI results for model B

Table 2 Most and least environmental efficient countries (model B)

\begin{tabular}{l|l|l}
\hline Efficiency & Countries & SBEI \\
\hline Most efficient countries & Australia & 1.000 \\
\cline { 2 - 3 } & Estonia & 1.000 \\
\cline { 2 - 3 } & Hong Kong & 1.000 \\
\hline & Israel & 1.000 \\
\cline { 2 - 3 } & Jordan & 1.000 \\
\cline { 2 - 3 } & Kazakhstan & 1.000 \\
\cline { 2 - 3 } & Luxembourg & 1.000 \\
\cline { 2 - 3 } & Moldova & 1.000 \\
\hline & Morocco & 1.000 \\
\hline & Saudi Arabia & 1.000 \\
\hline \multirow{4}{*}{ Least efficient countries } & Indonesia & 0.737 \\
\cline { 2 - 3 } & Gabon & 0.680 \\
\cline { 2 - 3 } & Japan & 0.613 \\
\hline & China & 0.514 \\
\cline { 2 - 3 } & Congo & 0.398 \\
\hline
\end{tabular}

In order to overcome this problem, several ways have been proposed to increase the discriminatory power of DEA, as, for example, applying principal component analysis to reduce the dimensionality of inputs and/or outputs; however, this type of formulation exceeds the scope of the proposed modeling. 


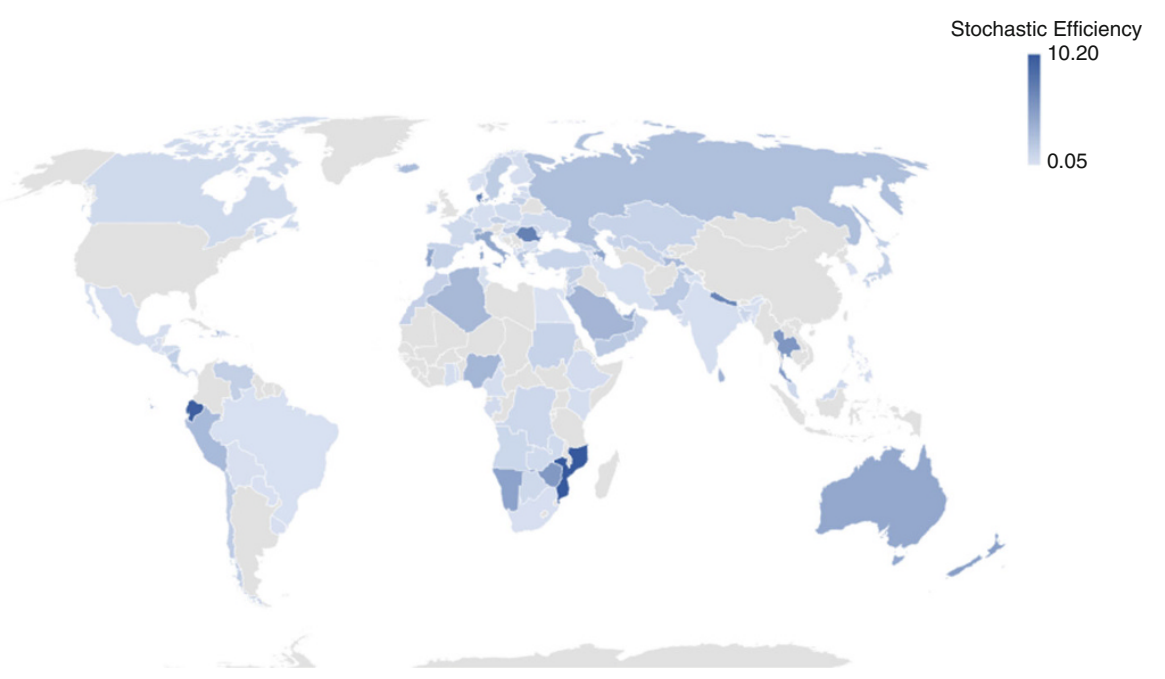

Fig. 4 Efficiency results for stochastic DEA model

\subsection{Stochastic Efficiency}

The stochastic efficiency results of the DEA model presented in Sect. 3.4 are shown in Fig. 4. Similarly to the previous sections, the results refer to the geometric mean of stochastic efficiency, while the different shades of color represent different values of stochastic efficiency (darker shades correspond to higher stochastic efficiency). The countries that were not considered in the analysis are painted with gray.

These results are quite different compared to the previous model due to the large variation of undesirable outputs (i.e., emissions) in some cases. It should be noted that due to its nature, the range of the stochastic efficiency score is larger, as shown in Fig. 4.

The results of the stochastic DEA model give the ability to sort countries based on the estimated efficiency scores. As shown in Table 3, countries may be categorized in three main groups:

(a) Counties with $\theta>1$ : This group refers to countries that are stochastic efficient and includes counties that, based on the previous results, are expected to be environmental efficient, like Australia, Luxembourg, Israel, Switzerland, Saudi Arabia, or the United Arab Emirates. However, additional developed (e.g., Denmark, New Zealand, Russian Federation, Portugal, Italy) and developing countries (e.g., Mozambique, Zimbabwe, Lebanon, Yemen, Pakistan) are included in this group. This phenomenon is ought to the fact that these countries utilize low resources to produce medium values of GDP but higher values of harmful emissions. 
Table 3 Categorization of countries based on stochastic efficiency scores

\begin{tabular}{|c|c|c|c|}
\hline \multirow{2}{*}{$\begin{array}{l}\text { Stochastic efficiency } \\
\theta>1\end{array}$} & \multicolumn{3}{|l|}{ Countries } \\
\hline & Mozambique & Portugal & Tajikistan \\
\hline & Ecuador & Italy & Peru \\
\hline & Denmark & Australia & Iceland \\
\hline & Romania & United Arab Emirates & Russian Federation \\
\hline & Nepal & Sri Lanka & Israel \\
\hline & Thailand & Switzerland & Luxembourg \\
\hline & Zimbabwe & Saudi Arabia & Lebanon \\
\hline & New Zealand & Haiti & Greece \\
\hline & Namibia & Nigeria & Yemen \\
\hline & Azerbaijan & Algeria & Pakistan \\
\hline \multirow[t]{8}{*}{$\theta \simeq 1$} & Costa Rica & Czech Republic & Sudan \\
\hline & Hungary & Venezuela & Jordan \\
\hline & Netherlands & Syria & Ireland \\
\hline & Chile & Japan & Kazakhstan \\
\hline & Sweden & Moldova & Cyprus \\
\hline & Oman & Morocco & Turkey \\
\hline & Nicaragua & Spain & Georgia \\
\hline & Lithuania & Uzbekistan & \\
\hline \multirow[t]{16}{*}{$\theta<1$} & Bangladesh & FYROM & Republic of Korea \\
\hline & Belgium & Latvia & South Africa \\
\hline & Angola & El Salvador & India \\
\hline & Congo & Ethiopia & Norway \\
\hline & Botswana & Guatemala & Bulgaria \\
\hline & Malaysia & Dominican Republic & Germany \\
\hline & Honduras & Philippines & Jamaica \\
\hline & France & Mexico & Iran \\
\hline & Canada & Ghana & Slovakia \\
\hline & Ukraine & Cameroon & Tunisia \\
\hline & Zambia & Albania & Brazil \\
\hline & Estonia & Finland & Croatia \\
\hline & Poland & Armenia & Paraguay \\
\hline & Gabon & Kenya & Bolivia \\
\hline & Bahrain & Panama & Egypt \\
\hline & Togo & Uruguay & Tanzania \\
\hline
\end{tabular}

(b) Countries with $\theta \simeq 1$ : Several countries are ranked lower based on stochastic DEA method. Some of them refer to Cyprus or Kazakhstan that appear to have higher efficiency in the previous DEA models. In general, some of the strong national economies are included in this group, like Netherlands, Sweden, and Spain. 
Table 4 Comparison of selective counties' ranking based on efficiency scores

\begin{tabular}{l|c|c|l}
\hline Stochastic efficiency & Model A & Model B & Stochastic DEA \\
\hline Australia & 1 & 1 & 13 \\
\hline France & 100 & 56 & 61 \\
\hline Germany & 84 & 92 & 91 \\
\hline Greece & 56 & 42 & 28 \\
\hline India & 108 & 97 & 88 \\
\hline Italy & 75 & 40 & 12 \\
\hline Japan & 76 & 102 & 46 \\
\hline Luxembourg & 1 & 1 & 26 \\
\hline Russian Federation & 94 & 75 & 24 \\
\hline Spain & 91 & 80 & 45 \\
\hline Sweden & 80 & 22 & 35 \\
\hline
\end{tabular}

(c) Countries with $\theta<1$ : This group refers to inefficient countries and includes both developed and developing countries. Countries with strong economies like France, Canada, Germany, or Finland are ranked quite low, as it can be seen in Table 3, since the standard deviation presents large fluctuations, while the probability levels for the undesirable outputs are also high.

The results of the stochastic DEA model, although appear to have some similarities with the slack-based DEA model, in several cases, they provide very different efficiency scores. Table 4, for example, shows the comparison of rankings obtained by the three alternative DEA models for selective countries. As it can be observed, in some cases the stochastic DEA model estimates larger efficiencies compared to slack-based models (e.g., Greece, Italy, Japan), while in other cases, the estimated efficiencies are lower (e.g., Luxembourg, Russia, Spain).

Finally, it should be noted that environmental efficiency should not be confused with environmental performance, since different combinations and levels of inputs may result to an environmental efficient production system.

\section{Concluding Remarks}

The aim of the present study is to present a methodological framework for the measurement of environmental efficiency and to highlight the evaluation indicators of the production units studied. To this end, a nonparametric method, data envelopment analysis, is applied. The study of environmental efficiency, in the context of DEA approaches, is mainly focused on analyzing how, with a given set of resources (inputs), the outcomes may be maximized (desirable outputs), while at the same time, emissions are minimized (undesirable outputs). 
Alternative SBM models are applied in this chapter under CRS and VRS technologies. The considered inputs and outputs have resulted in significant differentiations of the composite index. More specifically, model A assumed to have two inputs and four outputs, providing a meaningful ranking of countries with justified possible sudden fluctuations in the behavior of decision units. Model B, with three inputs and four outputs, provided less reliable results. Several decision units showed maximum efficiency since the model had less discrimination power. The results of this work can be compared to those of similar studies, possibly using a different methodological framework, to give a more general and complete picture of the subject. Finally, a stochastic DEA model is presented to measure stochastic efficiency of countries assuming that the undesirable outputs are stochastic.

According to the results of SBEI of model A, Australia, Hong Kong, and Luxembourg are fully efficient. Due to legislation regarding the emissions (e.g., $\mathrm{CO}_{2}$ ) and low input to the process producing large values of GDP, Luxembourg appears as a fully efficient country. This finding can drive other countries to adopt Luxembourg's paradigm and adjust their legislation. This finding indicates that countries should produce high values of GDP with less labor force, capital, and energy production while minimizing undesirable outputs. Based on the results of model B, Australia is fully efficient. In this model, the results of SBEI are closer to 1 compared to the corresponding results of SBEI of model A. This is attributed to the fact that given the inputs and outputs of model B, less countries are inefficient or gather lower values of efficiency leading to less discriminatory power.

Uncertainty is measured with a stochastic DEA model which categorizes countries based on the stochastic efficiency according to three categories: stochastic efficiency greater than 1 , equal to 1 , and less than 1 .

The main limitations of this study refer to the availability of data and the selection of appropriate inputs and outputs. For example, similar to previous studies, the selected indicators are actually proxies of the actual variables that should be included (e.g., GDP is a proxy of the true financial outcome of a national economy, although it is affected by several other factors). Thus, future research efforts may study different combinations of resources and outcomes in the context of the presented DEA approaches.

Moreover, the analysis can be further enhanced in the future with the addition of multiple layers or production processes. In such an approach, efficiency and the corresponding environmental indices can be calculated with the use of network DEA modeling. Also, comparing environmental efficiency and performance (effectiveness) may provide useful results for developing appropriate environmental policies. In this context, SBEI may be compared with alternative environmental or sustainability performance indices (see Grigoroudis et al. 2012 for a review). Finally, combining the presented analysis with the Malmquist index may give additional results regarding the evolution of environmental efficiency in the examined period. 


\section{References}

Baležentis, T., Li, T., Streimikiene, D., \& Baležentis, A. (2016). Is the Lithuanian economy approaching the goals of sustainable energy and climate change mitigation? Evidence from DEA-based environmental performance index. Journal of Cleaner Production, 116, $23-31$.

Brockhoff, K. (1970). Quantification of marginal productivity of industrial research by estimating a production function for a single firm. German Economic Review, 8(3), 202-229.

Callens, I., \& Tyteca, D. (1999). Towards indicators of sustainable development for firms: A productive efficiency perspective. Ecological Economics, 28(1), 41-53.

Charnes, A., \& Cooper, W. W. (1963). Deterministic equivalents for optimizing and satisficing under chance constraints. Operations Research, 11(1), 18-39.

Cooper, W. W., Deng, H., Huang, Z., \& Li, S. X. (2002). Chance constrained programming approaches to technical efficiencies and inefficiencies in stochastic data envelopment analysis. Journal of the Operational Research Society, 53(12), 1347-1356.

Dyckhoff, H., \& Allen, K. (2001). Measuring ecological efficiency with data envelopment analysis (DEA). European Journal of Operational Research, 132(2), 312-325.

Färe, R., Grosskopf, S., \& Pasurka, C. (1986). Effects on relative efficiency in electric power generation due to environmental controls. Resources and Energy, 8(2), 167-184.

Färe, R., Grosskopf, S., \& Tyteca, D. (1996). An activity analysis model of the environmental performance of firms: Application to fossil-fuel-fired electric utilities. Ecological Economics, 18 (2), 161-175.

Farrell, M. J. (1957). The measurement of productive efficiency. Journal of the Royal Statistical Society, Series A (General), 120(3), 253-290.

Grigoroudis, E., Kouikoglou, V. S., \& Phillis, Y. A. (2012). Approaches for measuring sustainability. In P. Olla (Ed.), Global sustainable development and renewable energy systems (pp. 101-130). Hersey: IGI Global.

Gutiérrez, R., Gutiérrez-Sánchez, R., \& Nafidi, A. (2008). Trend analysis using nonhomogeneous stochastic diffusion processes. Emission of $\mathrm{CO}_{2}$; Kyoto protocol in Spain. Stochastic Environmental Research and Risk Assessment, 22(1), 57-66.

Korhonen, P. J., \& Luptacik, M. (2004). Eco-efficiency analysis of power plants: An extension of data envelopment analysis. European Journal of Operational Research, 154(2), 437-446.

Mardani, A., Zavadskas, E. K., Streimikiene, D., Jusoh, A., \& Khoshnoudi, M. (2017). A comprehensive review of data envelopment analysis (DEA) approach in energy efficiency. Renewable and Sustainable Energy Reviews, 70, 1298-1322.

Prieto, A. M., \& Zofío, J. L. (2007). Network DEA efficiency in input-output models: With an application to OECD countries. European Journal of Operational Research, 178(1), 292-304.

Ramanathan, R. (2005). An analysis of energy consumption and carbon dioxide emissions in countries of the Middle East and North Africa. Energy, 30(15), 2831-2842.

Reinhard, S., Lovell, C. K., \& Thijssen, G. J. (2000). Environmental efficiency with multiple environmentally detrimental variables; estimated with SFA and DEA. European Journal of Operational Research, 121(2), 287-303.

Sueyoshi, T., Yuan, Y., \& Goto, M. (2017). A literature study for DEA applied to energy and environment. Energy Economics, 62, 104-124.

Triantis, K., \& Otis, P. (2004). Dominance-based measurement of productive and environmental performance for manufacturing. European Journal of Operational Research, 154(2), 447-464.

Tyteca, D. (1996). On the measurement of the environmental performance of firms: A literature review and a productive efficiency perspective. Journal of Environmental Management, 46(3), 281-308.

Zaim, O. (2004). Measuring environmental performance of state manufacturing through changes in pollution intensities: A DEA framework. Ecological Economics, 48(1), 37-47. 
Zha, Y., Zhao, L., \& Bian, Y. (2016). Measuring regional efficiency of energy and carbon dioxide emissions in China: A chance constrained DEA approach. Computers \& Operations Research, 66, 351-361.

Zhou, P., Ang, B. W., \& Poh, K. L. (2006). Slacks-based efficiency measures for modeling environmental performance. Ecological Economics, 60(1), 111-118.

Zhou, P., Poh, K. L., \& Ang, B. W. (2007). A non-radial DEA approach to measuring environmental performance. European Journal of Operational Research, 178(1), 1-9.

Zhou, P., Ang, B. W., \& Poh, K. L. (2008). Measuring environmental performance under different environmental DEA technologies. Energy Economics, 30(1), 1-14.

Zofío, J. L., \& Prieto, A. M. (2001). Environmental efficiency and regulatory standards: The case of $\mathrm{CO}_{2}$ emissions from OECD industries. Resource and Energy Economics, 23(1), 63-83.

Open Access This chapter is licensed under the terms of the Creative Commons Attribution 4.0 International License (http://creativecommons.org/licenses/by/4.0/), which permits use, sharing, adaptation, distribution and reproduction in any medium or format, as long as you give appropriate credit to the original author(s) and the source, provide a link to the Creative Commons license and indicate if changes were made.

The images or other third party material in this chapter are included in the chapter's Creative Commons license, unless indicated otherwise in a credit line to the material. If material is not included in the chapter's Creative Commons license and your intended use is not permitted by statutory regulation or exceeds the permitted use, you will need to obtain permission directly from the copyright holder. 